Supporting Information

\title{
X-ray Absorption Spectroscopy Investigation into the Origins of Heterogeneity in Silica-supported Dioxomonomolybdates
}

\author{
Li Li, ${ }^{a}$ Susannah L. Scott ${ }^{\mathrm{a}, \mathrm{b}, *}$ \\ ${ }^{a}$ Department of Chemistry \& Biochemistry, University of California, Santa Barbara, CA \\ 93106-9510, United States \\ ${ }^{\mathrm{b}}$ Department of Chemical Engineering, University of California, Santa Barbara CA 93106- \\ 5080, United States \\ *Correspondence to: sscott@ucsb.edu
}

\section{Table of contents}

Table S1 Mo pre-edge and K-edge positions for standards and grafted molybdates $\quad$ S2

Figure S2 Comparison of Mo K-edge XANES for $\mathrm{MoO}_{2} \mathrm{Cl}_{2}$ with data for $\mathrm{MoO}_{2}\left(\mathrm{OSiPh}_{3}\right)_{2}$, $\quad$ S3 $\mathrm{MoO}_{2}$ and $\mathrm{MoO}_{3}$

Figure S3 Comparison of the first derivative of the XANES for $\mathrm{MoO}_{2}\left(\mathrm{OSiPh}_{3}\right)_{2}, \mathrm{MoO}_{2} \mathrm{Cl}_{2}, \quad \mathrm{~S} 4$ $\mathrm{Na}_{2} \mathrm{MoO}_{4}$ and $\mathrm{MoO}_{2} \mathrm{Cl}_{2} / \mathrm{SiO}_{2}$

Figure S4 Curvefits of the non-phase-corrected Mo K-edge EXAFS for $\mathrm{MoO}_{2} \mathrm{Cl}_{2} / \mathrm{SiO}_{2}(\alpha$ is $\quad$ S5 the phase correction), before and after calcination, in $k^{3}$-weighed $k$ space

Figure S5 Non-phase-corrected $k^{3}$-weighted EXAFS ( $\alpha$ is the phase correction), for $\mathrm{Mo}=\mathrm{O}, \quad \mathrm{S} 6$ Mo-O and Mo-Cl paths in the curvefit of $\mathrm{MoO}_{2} \mathrm{Cl}_{2} / \mathrm{SiO}_{2}$.

Figure S6 $\chi(k)$ functions and FT magnitudes for Mo-Si and Mo-O-Si paths in EXAFS curvefit $\quad$ S7 of $\mathrm{MoO}_{2} \mathrm{Cl}_{2} / \mathrm{SiO}_{2}$

Table S2 EXAFS curvefit parameters for $\mathrm{Mo}(=\mathrm{O})_{2}(\mathrm{OSi})_{2}$ made from different precursors $\quad \mathrm{S} 7$

Figure S7 $\quad$ EXAFS of $\mathrm{Mo}(=\mathrm{O})_{2}(\mathrm{OSi})_{2}$ derived from $\mathrm{Mo}(=\mathrm{O})_{2}\left[\mathrm{OSi}\left(\mathrm{O}^{t} \mathrm{Bu}\right)_{3}\right]_{2} \quad \mathrm{~S} 8$

Figure S8 EXAFS of $\mathrm{Mo}(=\mathrm{O})_{2}(\mathrm{OSi})_{2}$ derived from $\mathrm{Mo}(=\mathrm{O})\left(\mathrm{O}^{t} \mathrm{Bu}\right)_{4} \quad \mathrm{~S} 8$

Figure S9 Simulated $\chi(k)$ functions for $\mathrm{Mo}=\mathrm{O}$ and $\mathrm{Mo}-\mathrm{O}$ paths, for grafted molybdates made $\quad \mathrm{S} 9$ by different routes

Figure S10 Sum of simulated $\chi(k)$ functions for two $\mathrm{Mo}=\mathrm{O}$ and two Mo-O paths, for grafted S10 molybdates made by different routes

Figure S11 Fourier transforms of simulated EXAFS (non-phase-corrected; $\alpha$ is the phase correction) for two $\mathrm{Mo}=\mathrm{O}$ and two Mo-O paths, for grafted molybdates made by different routes

Figure S12 Simulated $k^{3}$-weighted EXAFS (non-phase-corrected; a is the phase correction) for S12 two Mo-Si paths as a function of $\Delta R$

References 


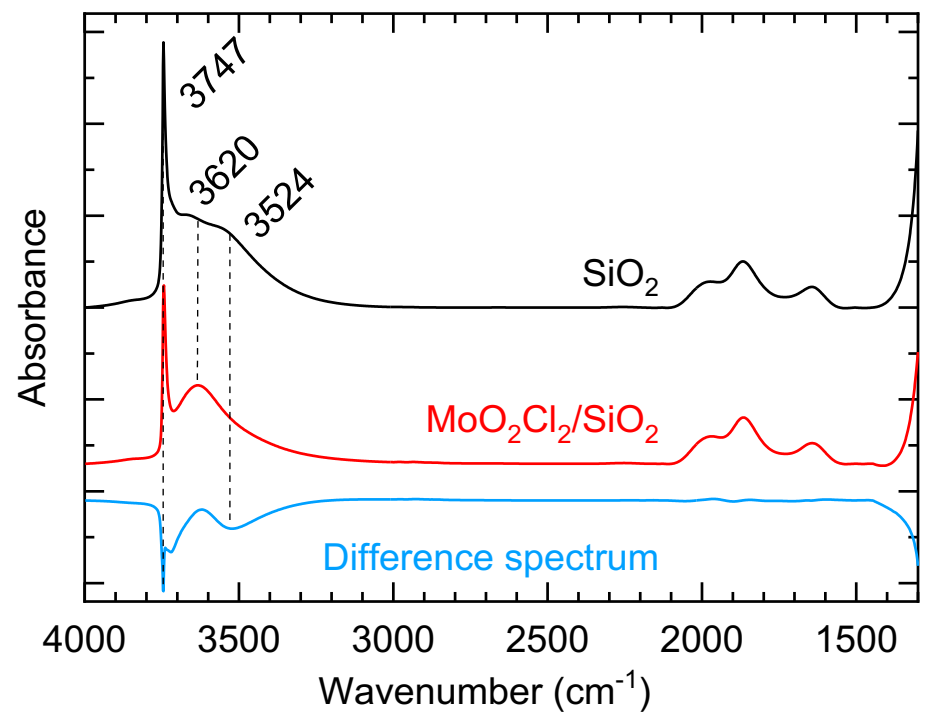

Figure S1. Difference (blue) between full IR spectra of silica (Aerosil A380, pretreated overnight at $200{ }^{\circ} \mathrm{C}$ under dynamic vacuum), before (black) and after (red) grafting $\mathrm{MoO}_{2} \mathrm{Cl}_{2}$ in a solid-solid reaction at room temperature. Both spectra were baselinecorrected, then normalized to the absorbance of the silica overtone at $1865 \mathrm{~cm}^{-1}$. The spectra are offset vertically for clarity.

Table S1. Mo pre-edge and K-edge positions a for standards and grafted molybdates

\begin{tabular}{lll}
\hline Compound or material & Pre-edge $/ \mathrm{eV}$ & Edge / eV \\
\hline $\mathrm{Mo}$ foil & N/A & $20,000.0^{\mathrm{b}}$ \\
$\mathrm{MoO}_{2}$ & N/A & $20,011.0$ \\
$\mathrm{MoO}_{2}\left(\mathrm{OSiPh}_{3}\right)_{2}$ & $20,003.2$ & $20,013.5$ \\
$\mathrm{MoO}_{2} \mathrm{Cl}_{2}$ & $20,004.2$ & $20,011.6$ \\
$\mathrm{Na}_{2} \mathrm{MoO}_{4}$ & $20,003.4$ & $20,016.7$ \\
$\mathrm{MoO}_{3}$ & $20,006.4$ & $20,015.0$ \\
$\mathrm{MoO}_{2} \mathrm{Cl}_{2} / \mathrm{SiO}_{2}$ & $20,004.3$ & $20,015.2$ \\
$\mathrm{MoO}_{\mathbf{x}} / \mathrm{SiO}_{2}$ & $20,004.4$ & $20,015.2$ \\
\hline
\end{tabular}

a The pre-edge position is defined as the position of the first peak in the Mo K-edge XANES (identified by the first zero-crossing in the first derivative of the XANES), while the edge position is defined as the first maximum after the pre-edge peak in the first derivative of the XANES. ${ }^{b}$ By convention. ${ }^{1}$ 

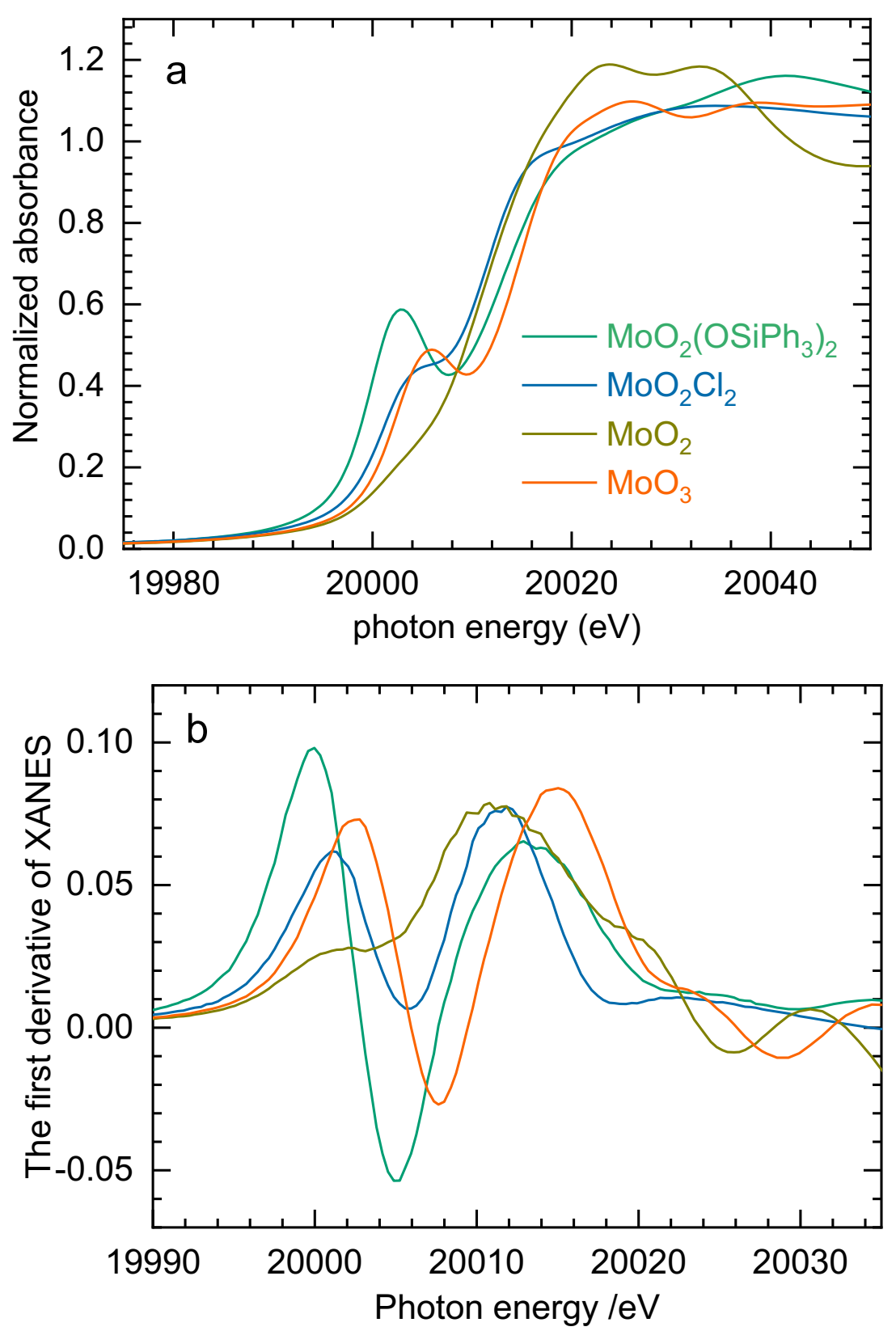

Figure S2. Comparison of Mo K-edge XAS for $\mathrm{MoO}_{2} \mathrm{Cl}_{2}$ (blue), with data for $\mathrm{MoO}_{2}\left(\mathrm{OSiPh}_{3}\right)_{2}$ (green), $\mathrm{MoO}_{2}$ (olive) and $\mathrm{MoO}_{3}$ (orange): (a) XANES, and (b) first derivative of the XANES. 


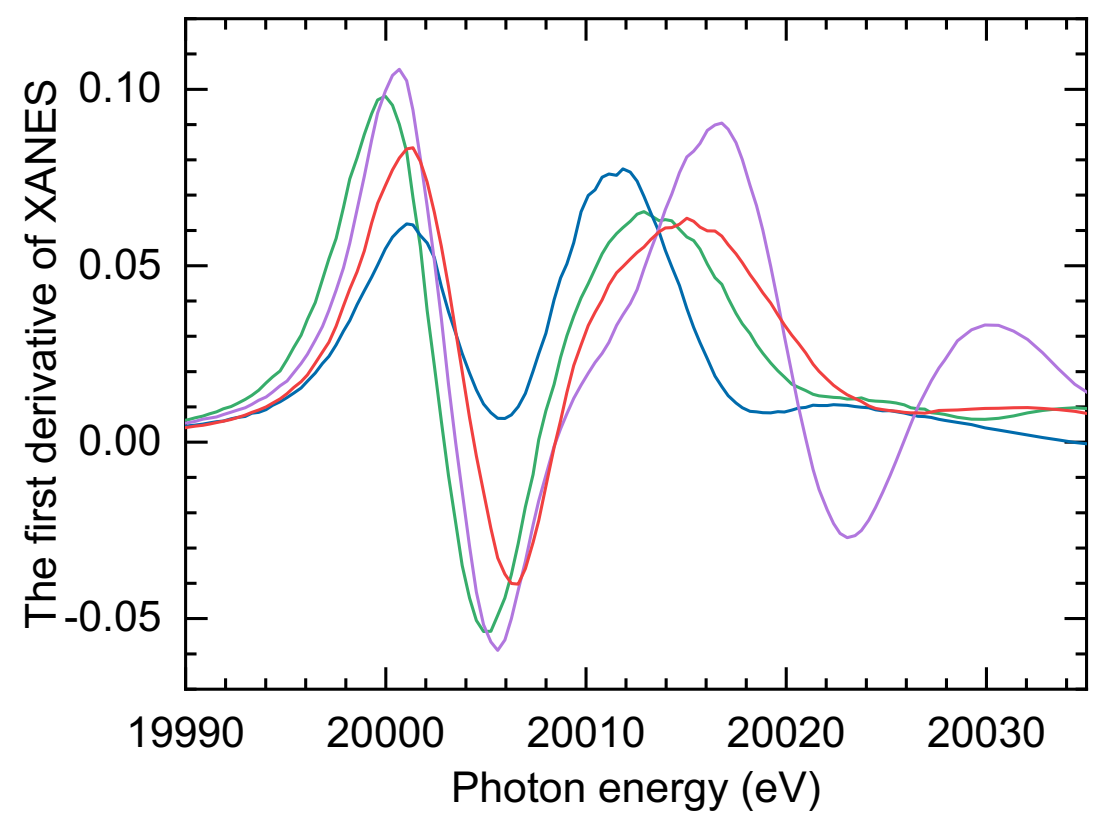

Figure S3. Comparison of the first derivatives of the XANES, for $\mathrm{MoO}_{2}\left(\mathrm{OSiPh}_{3}\right)_{2}$ (green), $\mathrm{MoO}_{2} \mathrm{Cl}_{2}$ (blue), $\mathrm{Na}_{2} \mathrm{MoO}_{4}$ (purple) and $\mathrm{MoO}_{2} \mathrm{Cl}_{2} / \mathrm{SiO}_{2}$ (red). 

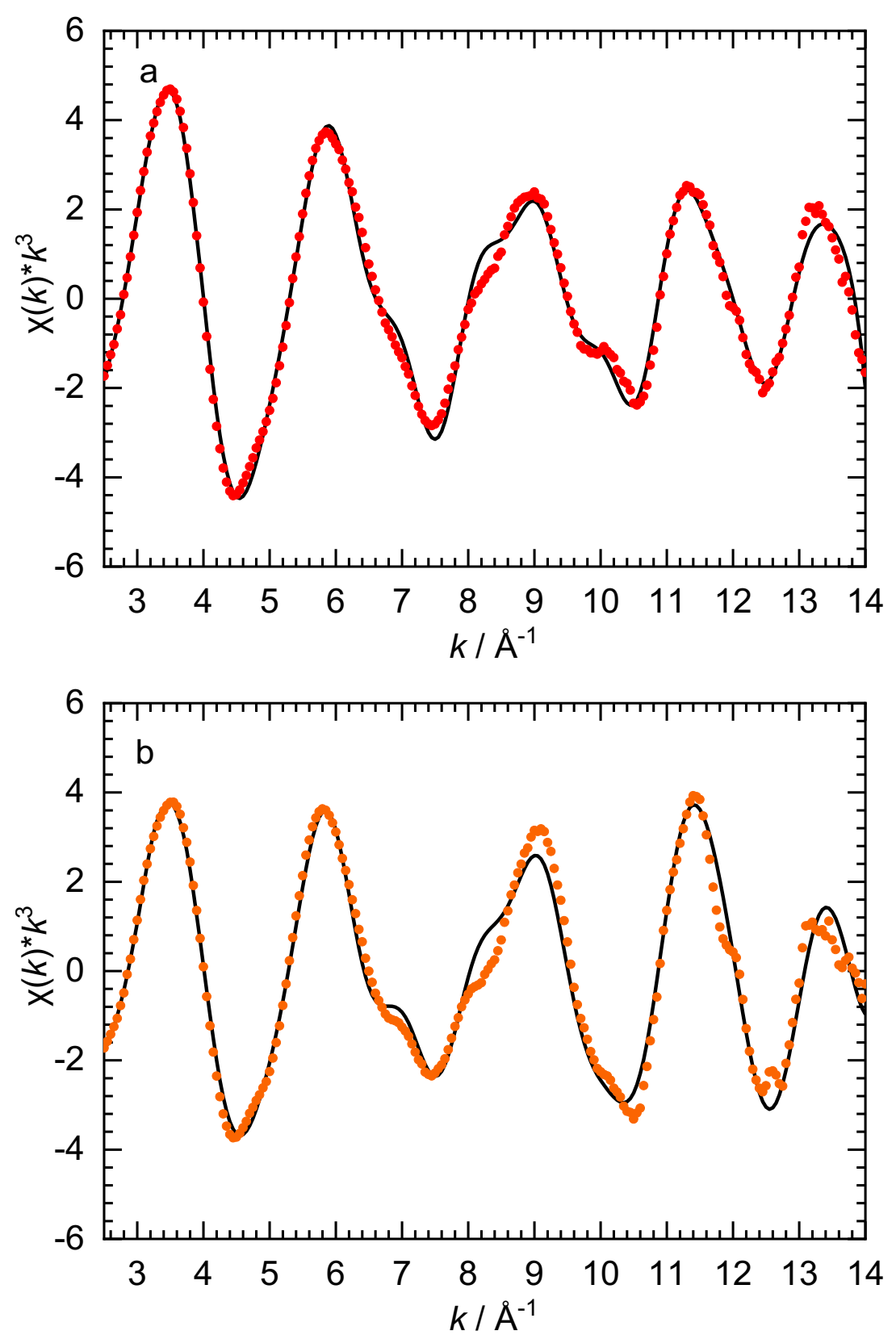

Figure S4. Curvefits (black lines) of the non-phase-corrected Mo K-edge EXAFS (points, $\alpha$ is the phase correction) in $k^{3}$-weighted $k$-space for $\mathrm{MoO}_{2} \mathrm{Cl}_{2} / \mathrm{SiO}_{2}$ : (a) before, and (b) after calcination. 


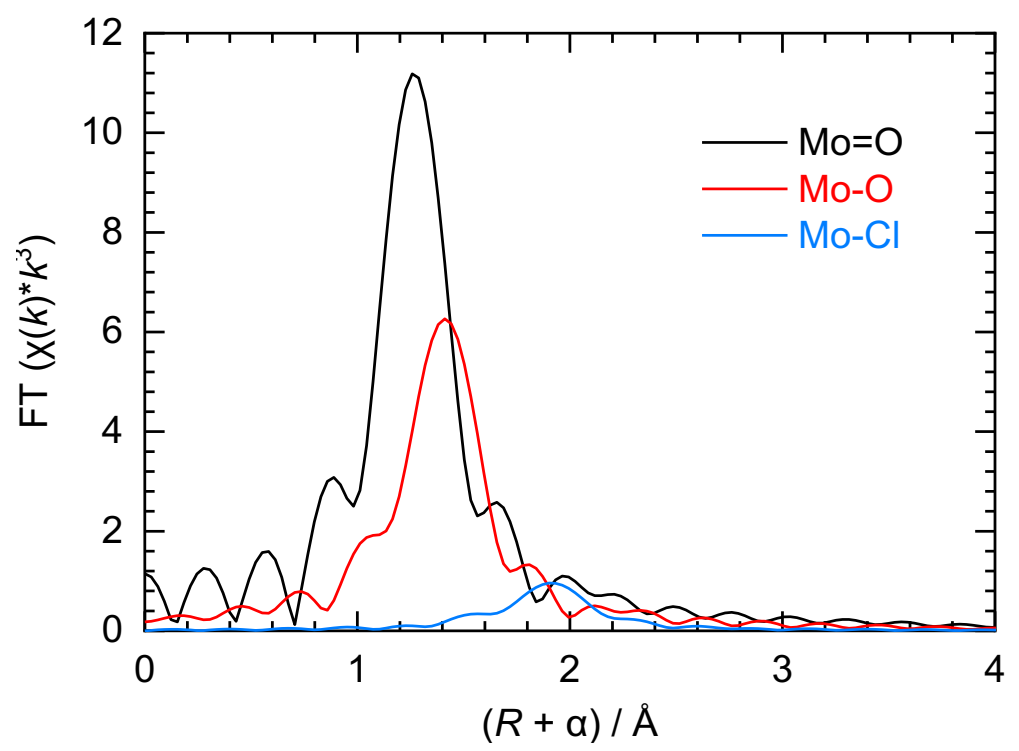

Figure S5. Non-phase-corrected $k^{3}$-weighed EXAFS ( $\alpha$ is the phase correction), for $\mathrm{Mo}=\mathrm{O}$, Mo$\mathrm{O}$ and $\mathrm{Mo}-\mathrm{Cl}$ paths in the curvefit of $\mathrm{MoO}_{2} \mathrm{Cl}_{2} / \mathrm{SiO}_{2}$. 

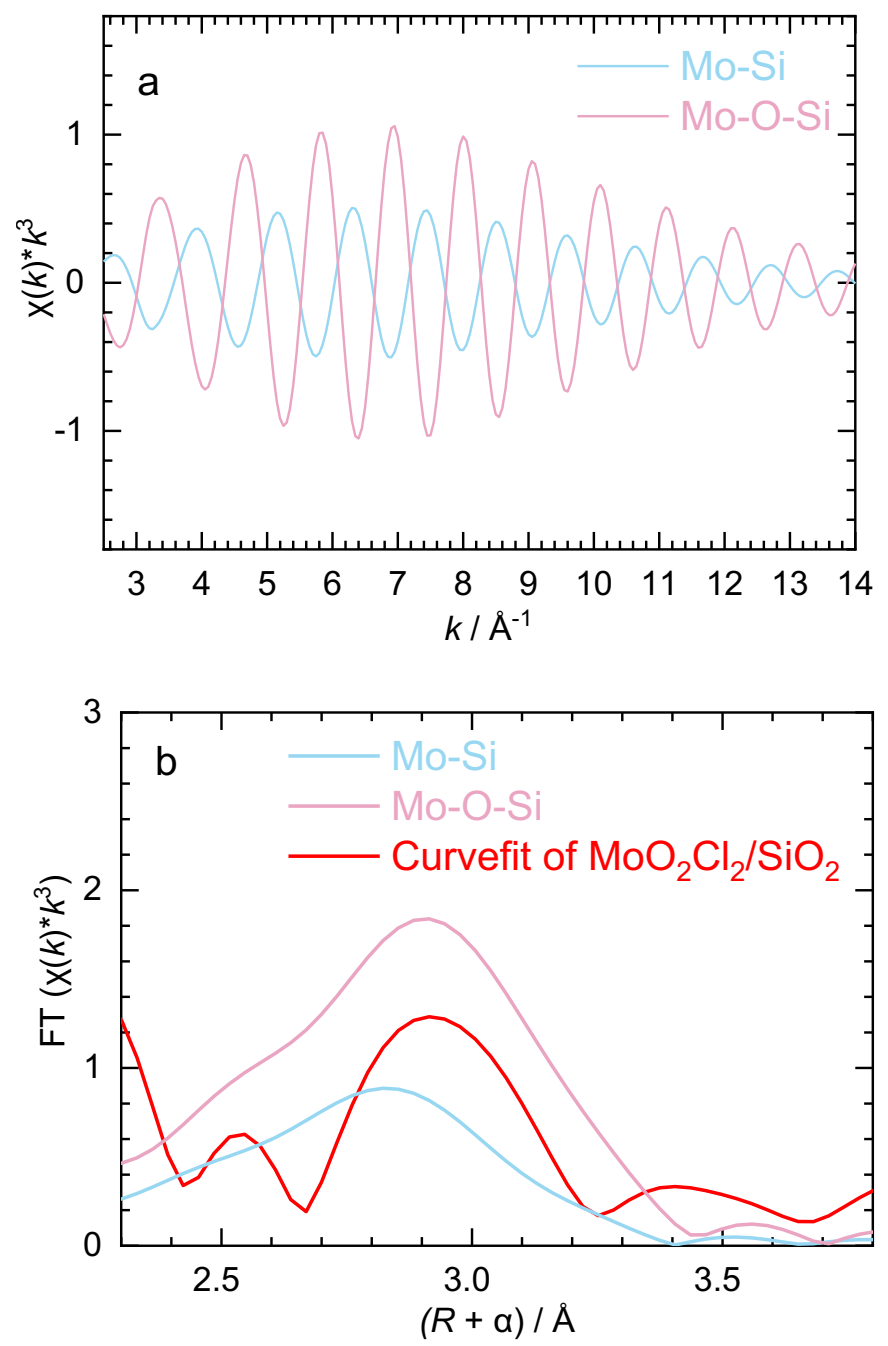

Figure S6. (a) $k^{3}$-weighted $\chi(k)$ functions, and (b) non-phase-corrected $k^{3}$-weighed FT magnitudes, for the Mo-Si single-scattering path (blue) and Mo-O-Si double-scattering path (pink), extracted from the EXAFS curvefit for $\mathrm{MoO}_{2} \mathrm{Cl}_{2} / \mathrm{SiO}_{2}$ (red).

Table S2. EXAFS curvefit parameters for $\mathrm{Mo}(=\mathrm{O})_{2}(\mathrm{OSi})_{2}$ made from different precursors

\begin{tabular}{|c|c|c|c|c|c|c|}
\hline \multirow[t]{2}{*}{ Precursor } & \multicolumn{2}{|c|}{$\mathrm{Mo}=\mathrm{O}$} & \multicolumn{2}{|c|}{ Мo-O } & \multicolumn{2}{|c|}{ Mo-Si } \\
\hline & $R / \AA$ & $\sigma^{2} / \AA^{2}$ & $R / \AA$ & $\sigma^{2} / \AA^{2}$ & $R / \AA$ & $\sigma^{2} / \AA^{2}$ \\
\hline $\mathrm{MoO}_{2} \mathrm{Cl}_{2}$ & $1.68(1)$ & $0.002(1)$ & $1.88(2)$ & $0.003(1)$ & $3.48(4)$ & $0.007(3)$ \\
\hline $\mathrm{MoO}_{2}\left[\mathrm{SiO}\left(\mathrm{O}^{t} \mathrm{Bu}\right)_{3}\right]_{2}{ }^{\mathrm{a}}$ & $1.699(5)$ & $0.0019(5)$ & $1.921(6)$ & $0.0032(11)$ & $\begin{array}{l}3.39(5), \\
3.52(5)\end{array}$ & $0.014(12)$ \\
\hline $\mathrm{MoO}\left(\mathrm{O}^{t} \mathrm{Bu}\right)_{4}^{\mathrm{b}}$ & $1.705(10)$ & $0.0021(3)$ & $1.870(15)$ & $0.0026(4)$ & $3.27(5)$ & $0.011(7)$ \\
\hline
\end{tabular}

${ }^{\mathrm{a}}$ From ref. $2 .{ }^{\mathrm{b}}$ From ref. 3. 

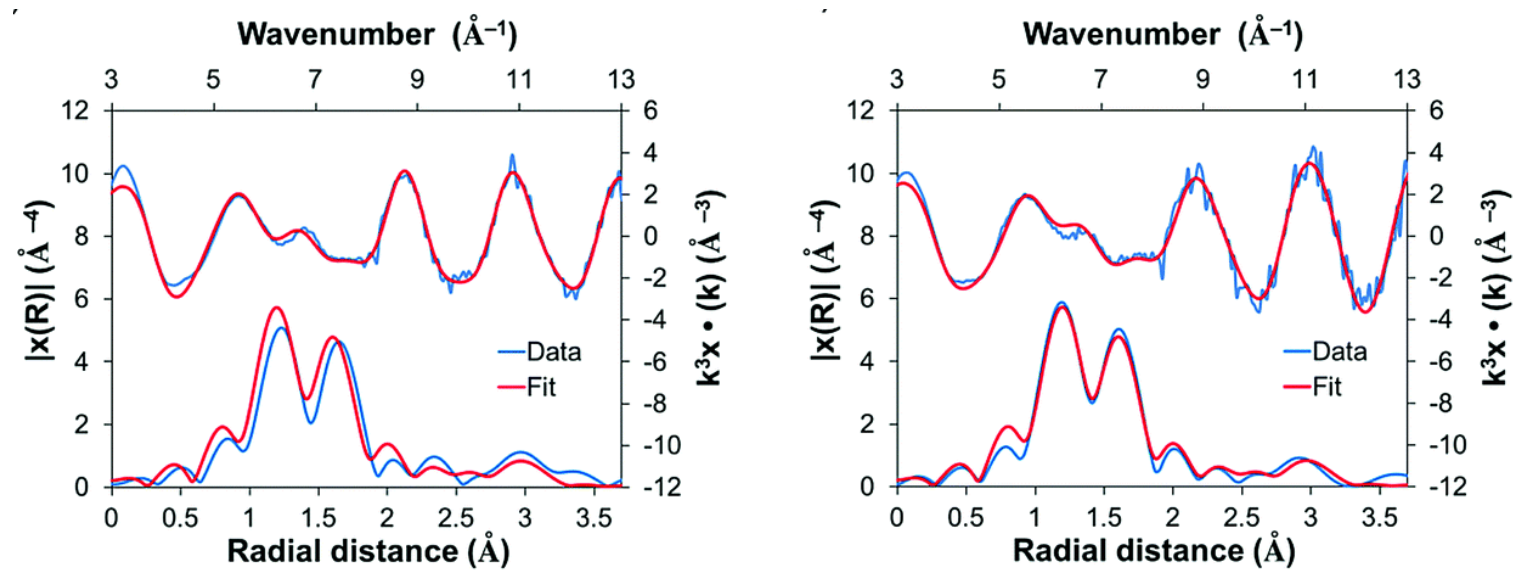

Figure S7. Mo K-edge EXAFS, in $k$-space (top) and $R$-space (bottom), and curvefits for $\mathrm{Mo}(\mathrm{O})_{2}\left[\mathrm{OSi}\left(\mathrm{O}^{t} \mathrm{Bu}\right)_{3}\right]_{2}$ (left) and $(\equiv \mathrm{SiO})_{2} \mathrm{Mo}(\mathrm{O})_{2}$ made by grafting $\mathrm{Mo}(\mathrm{O})_{2}\left[\mathrm{OSi}\left(\mathrm{O}^{t} \mathrm{Bu}\right)_{3}\right]_{2}$ onto silica followed by calcination (right). ${ }^{2}$ Reproduced from Ref. 2 , with permission from the Royal Society of Chemistry.
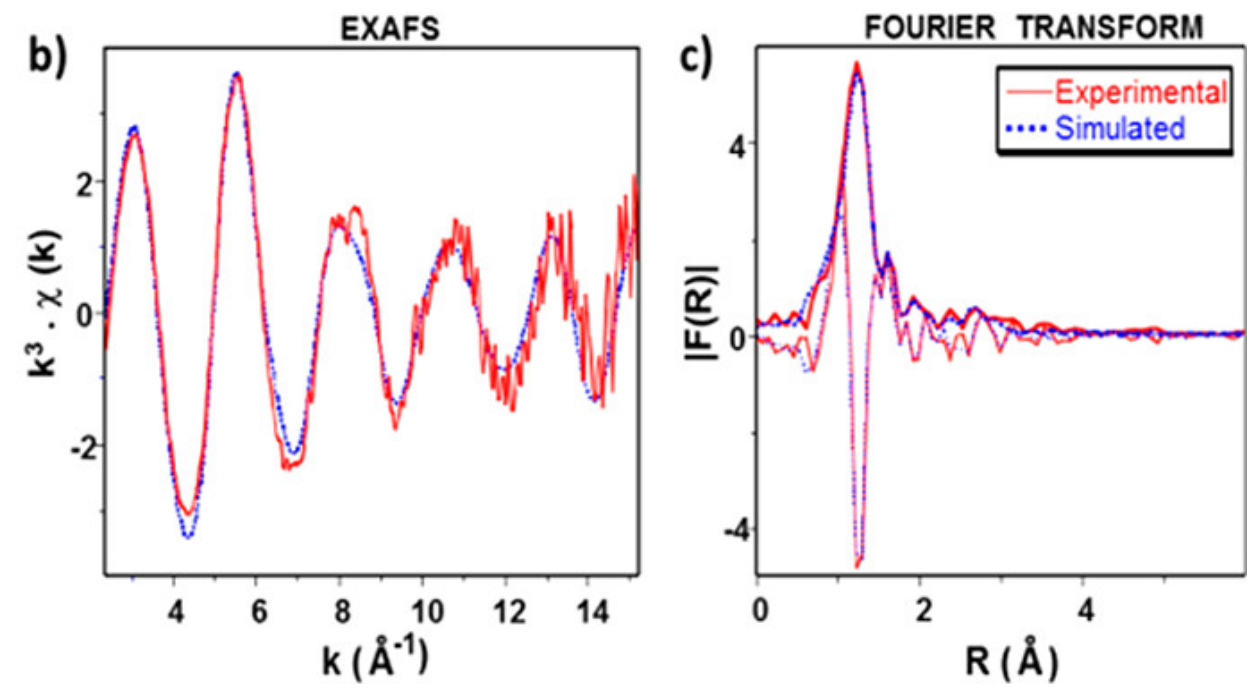

Figure S8. Mo K-edge EXAFS, in $k$-space (left) and $R$-space (right) for $(\equiv \mathrm{SiO})_{2} \mathrm{Mo}(\mathrm{O})_{2}$ made by grafting $\mathrm{Mo}(=\mathrm{O})\left(\mathrm{O}^{t} \mathrm{Bu}\right)_{4}$ onto silica followed by mild heating. ${ }^{3}$ Reprinted with permission from ref 3. Copyright 2018 American Chemical Society. 

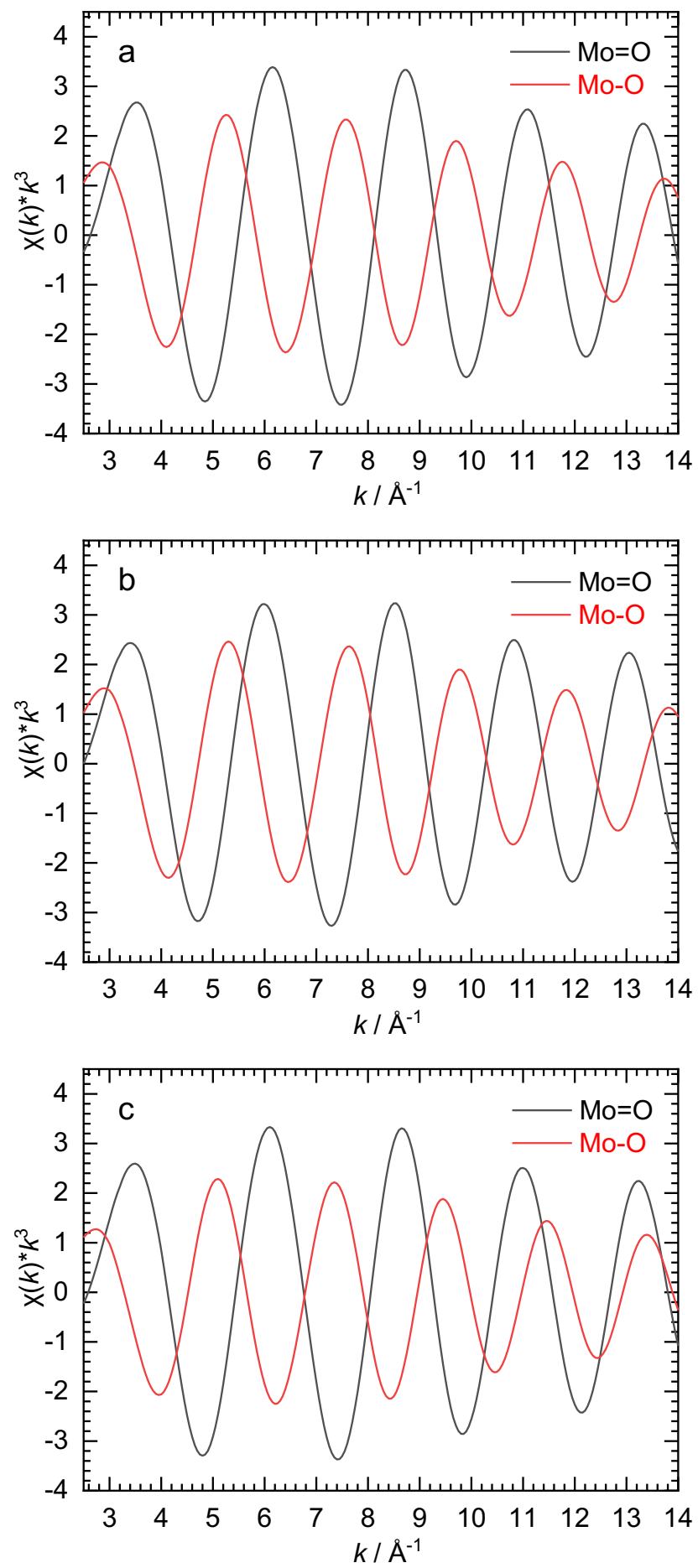

Figure S9. Individual simulated $k^{3}$-weighted $\chi(k)$ functions for two $\mathrm{Mo}=\mathrm{O}$ (black) and two Mo-O (red) paths at (a) 1.68 and $1.87 \AA$ (this work); (b) 1.71 and $1.86 \AA$ (i.e., slightly longer $\mathrm{Mo}=\mathrm{O}$ path, according to ref. 2); (c) 1.69 and $1.91 \AA$ (i.e., slightly longer Mo-O path, according to ref 3), corresponding to curvefit distances reported for grafted molybdates made by different routes. The following parameters were fixed in the simulation: $S_{0}^{2}=1, \Delta E_{0}=0 \mathrm{eV}, \sigma^{2}(\mathrm{Mo}=\mathrm{O})=0.002 \AA^{2}, \sigma^{2}(\mathrm{Mo}-\mathrm{O})=0.003 \AA^{2}$ 

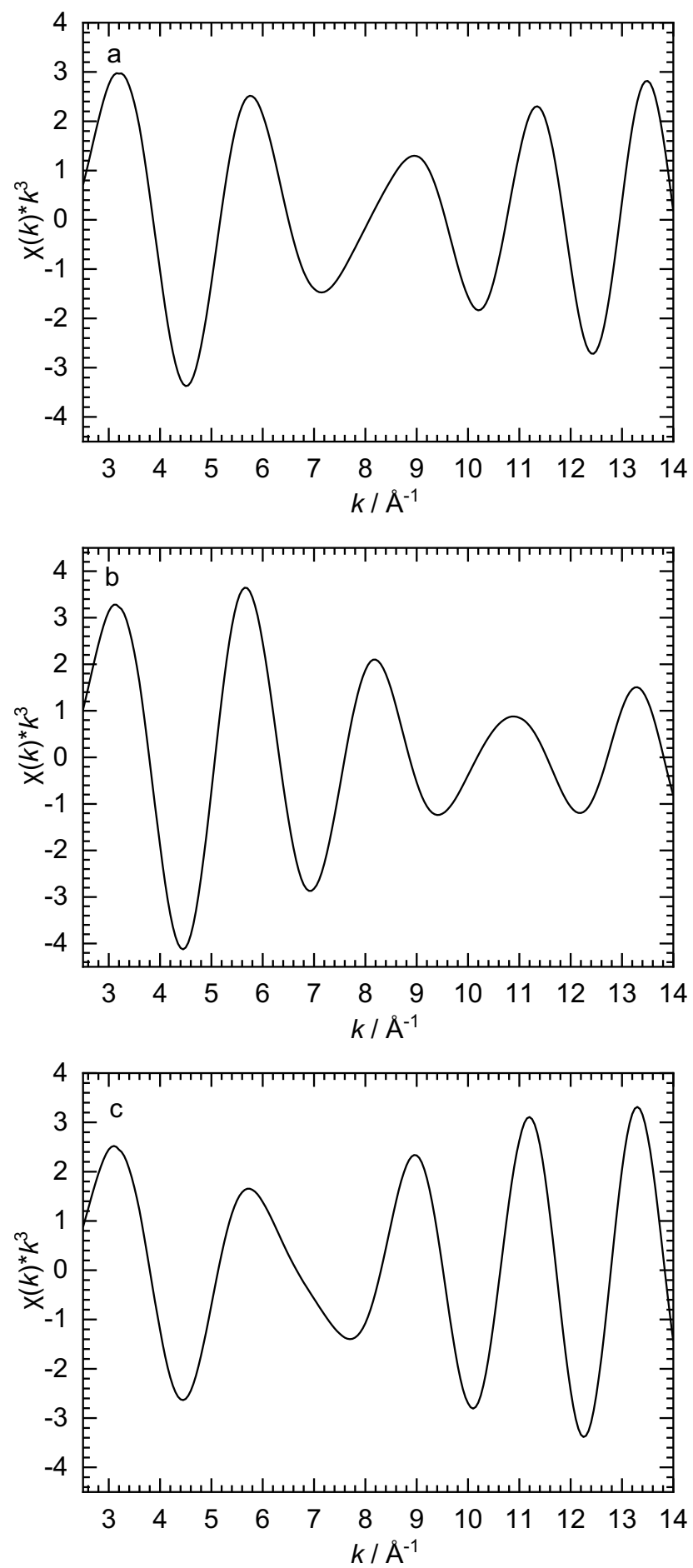

Figure S10. The sum of the simulated $k^{3}$-weighted $\chi(k)$ functions shown in Figure S8 for two $\mathrm{Mo}=\mathrm{O}$ and two Mo-O paths at (a) 1.68 and $1.87 \AA$ (this work); (b) 1.71 and $1.86 \AA$ (ref 2); (c) 1.69 and $1.91 \AA$ (ref 3), corresponding to curvefit distances reported for grafted molybdates made by different routes. 

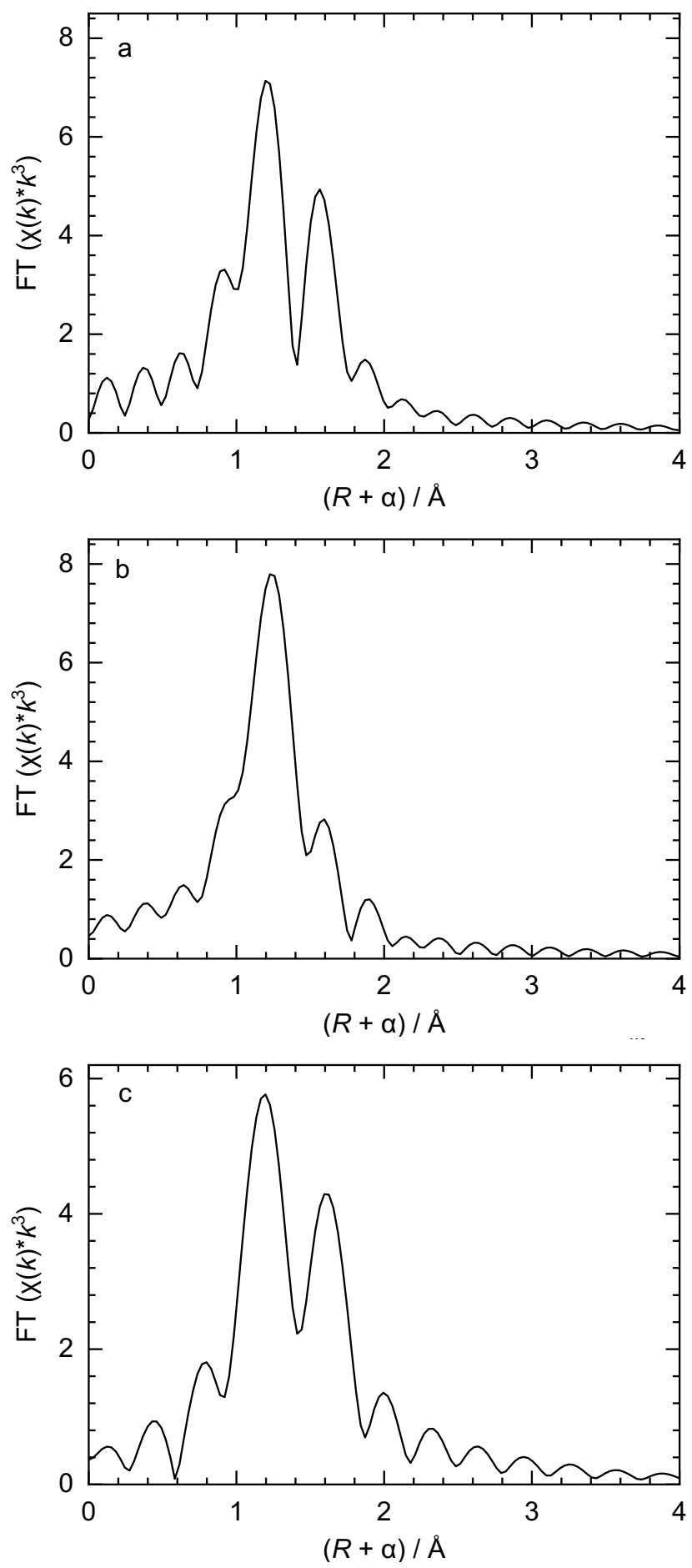

Figure S11. Fourier transforms of the simulated non-phase-corrected EXAFS ( $\alpha$ is the phase correction) shown in Figure $\mathrm{S} 9$, for two $\mathrm{Mo}=\mathrm{O}$ and two Mo-O paths at (a) 1.68 and $1.87 \AA$ (this work); (b) 1.71 and $1.86 \AA$ (ref 2); (c) 1.69 and $1.91 \AA$ (ref 3), corresponding to curvefit distances reported for grafted molybdates made by different routes. 

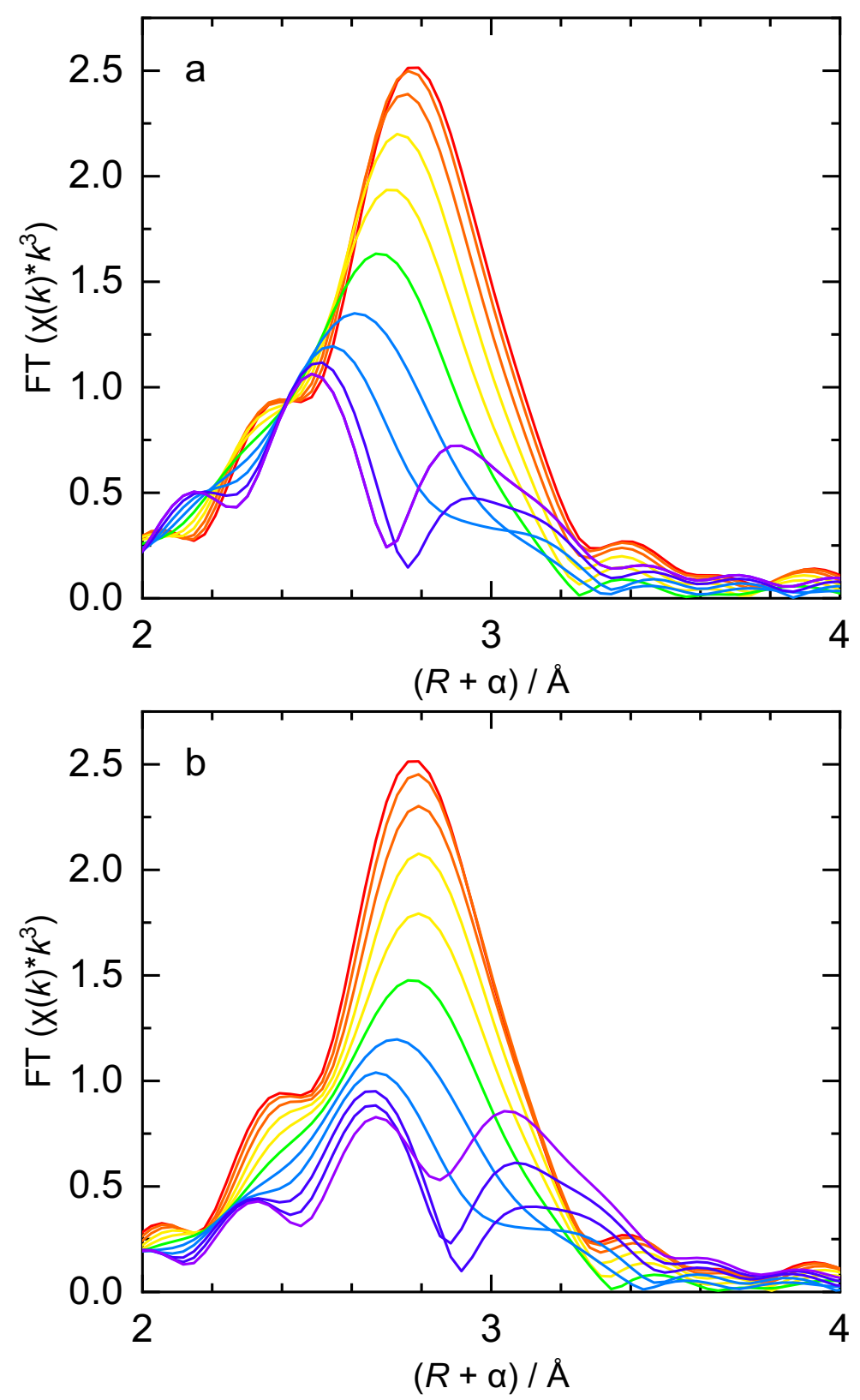

Figure S12. Simulation of the non-phase-corrected $k^{3}$-weighed EXAFS ( $\alpha$ is the phase correction) for two Mo-Si paths. One Mo-Si distance is fixed at 3.264 $\AA$, while the second Mo-Si distance varies. The spectra show the effect of differences in path length $(\Delta R)$ : (a) from 0 to $-0.2 \AA$; and (b) from 0 to $+0.2 \AA$, in intervals of $0.02 \AA$. Colors from red to purple reflect the increasing magnitude of $\Delta R$. The following parameters were held fixed in the simulation: $S_{0}^{2}=0.98, \Delta E_{0}=0 \mathrm{eV}, \sigma^{2}=0.003 \AA^{2}$. 


\section{References}

1. Thompson, A. C.; Vaughan, D., X-ray data booklet. Lawrence Berkeley National Laboratory, University of California Berkeley, CA: 2001; Vol. 8.

2. Yamamoto, K.; Chan, K. W.; Mougel, V.; Nagae, H.; Tsurugi, H.; Safonova, O. V.; Mashima, K.; Copéret, C. Silica-supported isolated molybdenum di-oxo species: formation and activation with organosilicon agent for olefin metathesis. Chem. Commun. 2018, 54, 3989-3992.

3. Le Quéméner, F.; Barman, S.; Merle, N.; Aljuhani, M. A.; Samantaray, M. K.; Saih, Y.; Szeto, K. C.; De Mallmann, A.; Minenkov, Y.; Huang, K.-W.; et al. Metathetic Oxidation of 2-Butenes to Acetaldehyde by Molecular Oxygen Using the Single-Site Olefin Metathesis Catalyst $(\equiv \mathrm{SiO})_{2} \mathrm{Mo}(=\mathrm{O})_{2}$. ACS Catal. 2018, 8, 7549-7555. 